\title{
Efficacy of iron rich Bajra chiwada on haemoglobin content of adolescent girls
}

\author{
R.H. Gore, T.N. Khan and J.P. Nerlekar
}

Food based approaches have higher potential for achieving far reaching and long lasting benefits for the control of iron and other micronutrient deficiencies. Keeping in view the present study was planned with the main objective to explore effectiveness of iron rich product popped Bajra chiwada (Pearl Millet) supplementation prepared by utilizing pearl pop, rajgira leaves, roasted bengal gram dhal, turmeric, mango powder, curry leaves and cumin on haemoglobin content of adolescent girls. 60 moderately anaemic adolescent girls were selected. They were divided into two group i.e. experimental group (30) and control group (30). The highly accepted iron rich popped Bajra chiwada was supplemented $50 \mathrm{~g} / \mathrm{day}$ to the experimental group for 60 days. The parameters such as anthropometric measurements and haemoglobin content were studied at 0,30 and 60 days. The investigation of study revealed that supplementation of 50 g. popped Bajra chiwada daily for the adolescent girls helped in improving the haemoglobin of the subjects.

Key Words : Haemoglobin content, Adolescent girls

How to cite this article : Gore, R.H., Khan, T.N. and Nerlekar, J.P. (2020). Efficacy of iron rich Bajra chiwada on haemoglobin content of adolescent girls. Food Sci. Res. J., 11(2): 84-88, DOI : 10.15740/HAS/FSRJ/11.2/84-88.Copyright@ 2020: Hind AgriHorticultural Society.

T.N. Khan, Department of Food Science and Nutrition, College of Community Science, Vasantrao Naik Marathwada Krishi Vidyapeeth, Parbhani (M.S.) India

Email: k_naheed@rediffmail.com

Associate Authors' :

R.H. Gore and J.P. Nerlekar, Department of Food Science and Nutrition, College of Community Science, Vasantrao Naik Marathwada Krishi Vidyapeeth, Parbhani (M.S.) India 